\title{
The effects of alkanolamide addition on cure characteristics, swelling behaviour and tensile properties of silica-filled natural rubber (NR) I chloroprene rubber (CR) blends
}

\author{
Indra Surya ${ }^{1 *^{*}}$, Syahrul Fauzi Siregar ${ }^{1}$, and Hanafi Ismail $^{2}$ \\ ${ }^{1}$ Department of Chemical Engineering, Faculty of Engineering, Universitas Sumatera Utara, Medan, \\ Sumatera Utara, Indonesia \\ ${ }^{2}$ School of Materials and Mineral Resources Engineering, Universiti Sains Malaysia, Penang, \\ Malaysia
}

\begin{abstract}
Effects of alkanolamide (ALK) addition on cure characteristics, swelling behaviour and tensile properties of silica-filled natural rubber (NR)/chloroprene rubber (CR) blends were investigated. The ALK was synthesized from Refined Bleached Deodorized Palm Stearin (RBDPS) and diethanolamine, and incorporated into the silica-filled NR/CR blends as a non-toxic rubber additive. The ALK loadings were 0.0, 1.0, 3.0, 5.0 and $7.0 \mathrm{phr}$. It was found that the ALK exhibited shorter scorch and cure times and higher elongation at break of the silica-filled NR/CR blends. The ALK also exhibited higher torque differences, tensile modulus and tensile strength at a $1.0 \mathrm{phr}$ of ALK loading and then decreased with further increases in the ALK loading. The swelling measurement proved that the $1.0 \mathrm{phr}$ loading of ALK caused the highest degree in crosslink density of the silica-filled NR/CR blends.
\end{abstract}

\section{Introduction}

Magnesium and zinc oxides $(\mathrm{MgO}$ and $\mathrm{ZnO})$ and ethylene thiourea (ETU) are widely utilised as the curative additives for chloroprene rubber (CR) [1-2]. Generally, $\mathrm{MgO}$ and $\mathrm{ZnO}$ are the vulcanising agents and ETU is the accelerator. ETU is a toxic material and is suspected to be carcinogenic [3-4]. Therefore, the appearance of an alternative vulcanisation accelerator for CR has been in demand.

Alkanolamide (ALK) is a relatively new rubber additive [5-11]. It can be prepared from refined bleached deodorised palm stearin (RBDPS), a by-product (waste) of palm cooking oil production, and ethanolamine. Since it comes from palm oil, ALK is a palm oil based rubber additive and it can be considered as a sustainable, (semi) renewable and non-toxic ingredient. ALK is a solid waxy material and it has some unique natures of the molecule which is structured by the combination of hydrophobic long chain hydrocarbon and hydrophilic amine. Due to its unique molecular structure, ALK has been utilised as a

*Corresponding author: indradanas@yahoo.com 
curative additive in rubber compounding. The hydrophobic part of the molecule has the tendency to interact with rubbers, especially non-polar rubbers such as natural rubber (NR), styrene butadiene rubber, etc. [5-7]. The hydrophilic amine interacted not only with the polar filler such as silica [5-6] but also with polar rubber such as epoxidised natural rubber [7]. The ALK also cross-linked the CR chains of carbon black-filled CR compounds [9]. Such interactions affected the cure characteristics and tensile/mechanical properties of the rubbers compounds.

Based on the above explanations, ALK is likely to yield some good results in replacing the carcinogenic ETU as a vulcanising agent. Therefore, this study reports the utilisation of ALK as a vulcanising agent for silica-filled NR/CR blends. The effects of ALK on cure characteristics, swelling behaviour and tensile properties of silica-filled NR/ CR blends were reported.

\section{Materials and methods}

\subsection{Materials}

NR grade SMR L was used and obtained from Guthrie (M) Sdn. Bhd., Seremban, Malaysia. Polychloroprene rubber (CR) [Skyprene B-30] was purchased from TOSOH Co. (Japan). Other compounding ingredients such as sulphur, zinc oxide, magnesium oxide, stearic acid, N-isopropyl-N'-phenyl-p-phenylenediamine (IPPD), N-cyclohexylbenzothiazyl-sulfenamide (CBS), Tetramethylthiuram disulfide (TMTD) and precipitated silica (grade Vulcasil - S) were supplied by Bayer (M) Ltd., Sdn. Bhd., Petaling Jaya, Selangor, Malaysia. All materials were used as supplied. The ALK was synthesized in the laboratory using Refined Bleached Deodorized Palm Stearin (RBDPS) and diethanolamine. Its molecular structure is shown in Fig. 1.<smiles>CCCCCCCCCCCCCCO</smiles>

Fig. 1. The molecular structure of alkanolamide.

\subsection{Compounding}

A semi-efficient vulcanization system was used for the rubber blending. The recipe for the preparation of the NR/CR blend is given in Table 1. The blending procedure was done in accordance with the American Society for Testing and Material (ASTM) - Designation D $3184-80$. The blending was done on a two-roll mill. Table 2 shows the designation and composition of the NR/CR blends used in this study. 
Table 1. The composition of silica-filled NR/CR blends without/with ALK.

\begin{tabular}{ll}
\hline Ingredients & Content $(\mathrm{phr})^{*}$ \\
\hline $\mathrm{NR} / \mathrm{CR}$ & $50 / 50$ \\
$\mathrm{ZnO}$ & 5.0 \\
$\mathrm{MgO}$ & 4.0 \\
Stearic acid & 1.0 \\
$\mathrm{IPPD}$ & 1.0 \\
$\mathrm{CBS}$ & 1.0 \\
$\mathrm{TMTD}$ & 0.5 \\
ETU & 0.5 \\
Sulphur & 2.0 \\
Silica & 30.0 \\
ALK & $0.0 ; 1.0 ; 3.0 ; 5.0 ; 7.0$ \\
\hline${ }^{*}$ parts per hundred parts of rubber blend &
\end{tabular}

Table 2. The designation and composition of the silica-filled NR/CR blends without and with ALK.

\begin{tabular}{ll}
\hline Designation & Composition \\
\hline NR/CR-0.0 (Control blend) & Silica-filled NR/CR blend without ALK \\
NR/CR-1.0 & Silica-filled NR/CR blend with ALK $(1.0 \mathrm{phr})$ \\
NR/CR-3.0 & Silica-filled NR/CR blend with ALK $(3.0 \mathrm{phr})$ \\
NR/CR-5.0 & Silica-filled NR/CR blend with ALK $(5.0 \mathrm{phr})$ \\
NR/CR-7.0 & Silica-filled NR/CR blend with ALK $(7.0 \mathrm{phr})$ \\
\hline
\end{tabular}

\subsection{Cure characteristics}

The cure characteristics of the rubber blends were obtained using a Monsanto Moving Die Rheometer (MDR 2000) which was employed to determine the scorch time ( $\left.\operatorname{ts}_{2}\right)$, cure time $\left(t_{90}\right)$ and torque difference $\left(\mathrm{M}_{\mathrm{H}}-\mathrm{M}_{\mathrm{L}}\right)$ value according to ISO 3417. Samples of the respective rubber blends were tested at $150{ }^{\circ} \mathrm{C}$. The rubber blends were subsequently compression-moulded using a stainless steel mould at $150{ }^{\circ} \mathrm{C}$, with a pressure of $10 \mathrm{MPa}$ and applying a laboratory hot-press based on respective curing times.

\subsection{Measurement of swelling behaviour}

Swelling behaviours were performed in toluene in accordance with ISO 1817. Cured test pieces (30 mmx5 mmx2 $\mathrm{mm}$ ) were weighed using an electrical balance and swollen in toluene until equilibrium, which took $72 \mathrm{~h}$ at room temperature. The samples were removed from the liquid, the toluene was removed from the sample surfaces, and the weight was determined. The change in mass is as follows:

$$
\text { Swelling }(\%)=100 \%\left(\mathrm{~W}_{2}-\mathrm{W}_{1}\right) / \mathrm{W}_{1}
$$

where $\mathrm{W}_{1}$ is the initial mass $(\mathrm{g})$ and $\mathrm{W}_{2}$ is the mass $(\mathrm{g})$ after immersion in toluene.

\subsection{Tensile properties}

Dumbbell-shaped samples were cut from the moulded sheets according to ISO 37. Tensile tests were performed at a crosshead speed of $500 \mathrm{~mm} / \mathrm{min}$. Tensile tests were carried out with a universal tensile machine Instron 3366 to determine the tensile properties in terms of tensile strength (TS), stresses at 100\% and 300\% elongations (M100, M300) and elongation at break (EB). 


\section{Results and discussions}

\subsection{Effect of ALK on cure characteristics of the silica-filled NR/CR blends}

Effect of ALK on the cure characteristics of the silica-filled NR/CR blends is showed in Table 3. The scorch and cure times decreased with increasing the ALK loadings. It was a cure enhancement which indicated ALK acted as a co-curing agent (secondary accelerator) in the curing. The amine content of the ALK caused the rubber blends more basic. Alkaline substances tend to improve the cure rate [12].

Table 3. The cure characteristics and tensile properties of silica-filled NR/CR blends without/with ALK.

\begin{tabular}{lccc|cccc}
\hline \multirow{2}{*}{$\begin{array}{l}\text { Rubber } \\
\text { blends }\end{array}$} & \multicolumn{3}{c|}{ Cure characteristics } & \multicolumn{4}{c}{ Tensile properties } \\
\cline { 2 - 8 } NR/CR-0.0 & 1.10 & 7.25 & 23.25 & 2.315 & 6.080 & 18.4 & 610.0 \\
NR/CR-1.0 & 1.09 & 6.03 & 25.02 & 2.391 & 6.200 & 21.2 & 636.7 \\
NR/CR-3.0 & 1.06 & 4.63 & 15.58 & 2.170 & 5.690 & 18.8 & 656.7 \\
NR/CR-5.0 & 1.05 & 4.33 & 14.05 & 2.069 & 5.370 & 16.8 & 701.7 \\
NR/CR-7.0 & 0.93 & 3.96 & 13.66 & 1.940 & 5.070 & 15.4 & 768.3 \\
\hline
\end{tabular}

Note: $\mathrm{M}_{\mathrm{L}}=$ Minimum torque; $\mathrm{M}_{\mathrm{H}}=$ Maximum torque; $\mathrm{M}_{\mathrm{H}}-\mathrm{M}_{\mathrm{L}}=$ Torque difference

The addition of $1.0 \mathrm{phr}$ of ALK increased the torque difference $\left(\mathrm{M}_{\mathrm{H}}-\mathrm{M}_{\mathrm{L}}\right)$. Further increases in the ALK loading decreased the torque difference. The torque difference represents shear dynamic modulus and it is believed that its value relates to the crosslink density of a rubber vulcanisate [8, 10, 13-14]. The addition of ALK affected the torque difference or the crosslink density of the silica-filled NR/CR blends. It was due to the action of the ALK as a secondary accelerator which enhanced the state of the curing process.

The reduction of crosslink density beyond $1.0 \mathrm{phr}$ of ALK loading was due to the softening or lubricating effect of the excessive ALK which dissolved a part of the elemental sulphur [7-8] and hence reduced crosslink density.

\subsection{Effect of ALK on swelling behaviour of the silica-filled NR/CR blends}

Effect of ALK loading on the swelling percentage of the silica-filled NR/CR blends with the error bar is shown in Fig. 2. The five-cured test pieces ( $30 \mathrm{~mm} 55 \mathrm{~mm} 2 \mathrm{~mm}$ ) of every rubber blend were weighed using an electrical balance and swollen in toluene until equilibrium, which took 72 hours at room temperature. The swelling percentage was measured by toluene uptake until equilibrium swelling was reached. It is widely used that the swelling is related to the crosslink density of a network chain [15], with less toluene uptake or penetration into the blends indicating a higher degree of crosslink density. Therefore, the swelling percentage of silica-filled NR/CR blend decreased with the addition of $1.0 \mathrm{phr}$ of ALK and increased with further increases in the ALK loading. The increases in swelling percentage might be due to the excessive loading of ALK which reduced the degree of crosslink density [7-8].

The results of swelling behaviour also showed that the swelling percentage have not much different for ALK loadings 3.0, 5.0 and $7.0 \mathrm{phr}$. It was due to, beyond the $3.0 \mathrm{phr}$, the function of ALK as a curative agent was less pronounced and hence, the swelling percentage or crosslink density was not much different. 


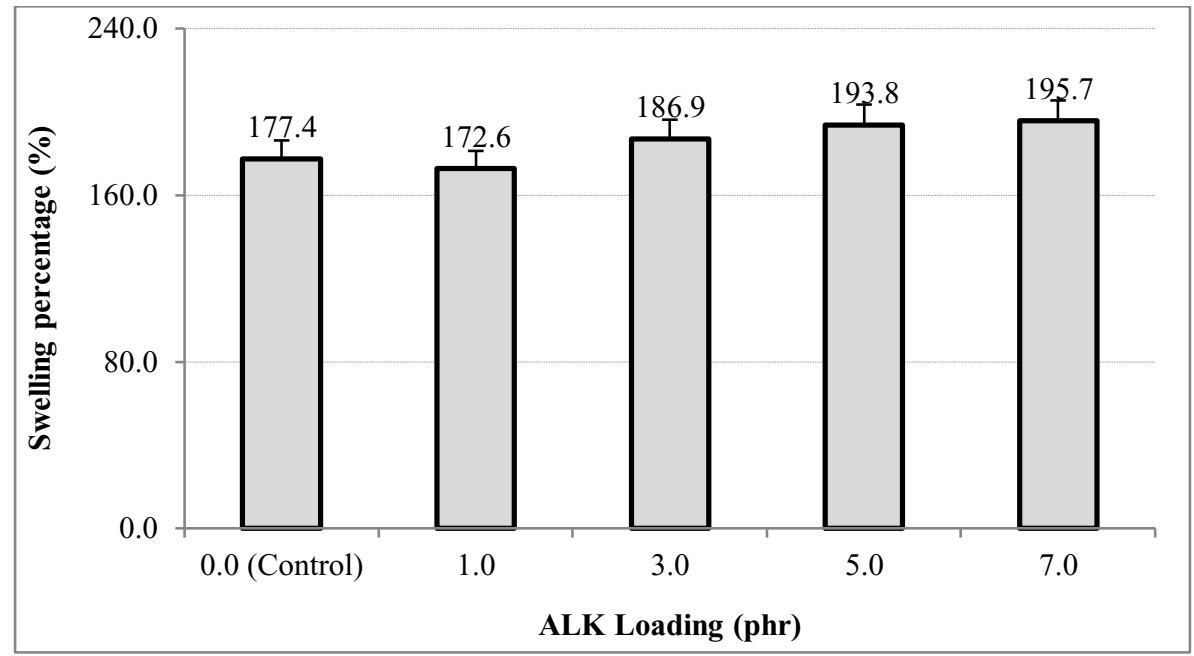

Fig. 2. Effect of alkanolamide loading on swelling percentage of silica-filled NR/CR blends.

\subsection{Effect of ALK on tensile properties of the silica-filled NR/CR blends}

Effect of ALK loading on the tensile properties of the silica-filled NR/CR blends is also shown in Table 3. The addition of $1.0 \mathrm{phr}$ ALK produced an NR/CR-1.0 rubber blend with a higher EB. Increasing the ALK loading caused further increases in the percentage of EB or the extensibility of the rubber blends. This was due to the function of ALK as an internal plasticiser which modified flexibility or distensibility of rubber blends [5-6].

The addition of ALK increased the M100 and M300 up to the maximum level at a 1.0 phr and decreased with further increases in the ALK loading. The results of tensile strength also exhibit the similar trend. Tensile modulus and tensile strength are dependent only on the degree of crosslink [5, 16-17]. The improvement of those properties was attributed to a higher degree of crosslink (as indicated by a higher value of torque difference). The deterioration of those properties was due to the excessive amount of ALK which dissolved other curative and hence reduced the degree of crosslink density (as indicated by a lower value of torque difference). As discussed earlier, the crosslink density of a rubber compound is indicated by torque difference value. The greater the torque difference, the higher is the degree or total crosslink density [8].

\section{Conclusions}

From this study, the following conclusions were drawn:

1. Alkanolamide was a curative additive in silica-filled natural rubber/chloroprene rubber blends.

2. Alkanolamide enhanced the cure rate, reduced the scorch and cure times and improved the flexibility by increasing the elongation at break.

3. Alkanolamide enhanced the tensile properties and crosslink density of the silica-filled natural rubber/chloroprene rubber blend especially at a $1.0 \mathrm{phr}$ of alkanolamide loading.

The authors would like to thank Universiti Sains Malaysia, for providing the research facilities for carrying out the experiment and for making this research work possible. Indra Surya and Syahrul Fauzi Siregar are grateful to Universitas Sumatera Utara for the Talenta research grant under contract No. 5338/UN5.1.R/PPM/ 2017 (22 May 2017). 


\section{References}

1. M. Akiba, A. Hashim, Prog. Polym. Sci 22, 475 (1997)

2. B. Rodgers, Chemistry and Applications (CRC, 2004)

3. R. Chhabra, S. Eustis, J. Haseman, P. Kurtz, B. Carlton, Fundam. Appl. Toxicol 18, 405 (1992)

4. D.M. Smith, Br J Ind Med 41, 362 (1984)

5. I. Surya, H. Ismail, A. Azura, Polym Test 32, 1313 (2013)

6. I. Surya, H. Ismail, A. Azura, Polym Test 40, 24 (2014)

7. I. Surya, H. Ismail, A. Azura, Polym Test 42, 208 (2015)

8. I. Surya, H. Ismail, Polym Test 50, 276 (2016)

9. I. Surya, H. Ismail, Plast Rubber and Compos 45, 287 (2016)

10. I. Surya, M. Ginting, H. Ismail, IOP Conf. Ser., Mater. Sci. Eng 223, 012006 (2017)

11. N. Hayeemasae, I. Surya, H. Ismail, Int J Polym Anal Charact 21, 396 (2016)

12. H. Long, Basic Compounding and Processing of Rubber (USA, 1985)

13. P. Teh, Z. Mohd Ishak, A. Hashim, J. Karger-Kocsis, U. Ishiaku, Eur. Polym. J 40, 2513 (2004)

14. H. Ismail, C. Ng, J Elastomers Plast 30, 308 (1998)

15. H. Nabil, H. Ismail, A. Azura, Polym Test 32, 385 (2013)

16. H. Ismail, H. Chia, Polym Test 17, 199 (1998)

17. I. Surya, SF Siregar, H. Ismail, IOP Conf. Ser., Mater. Sci. Eng 223, 012012 (2017) 